\title{
Organizational changes, trust, and information sharing: An empirical study
}

\begin{abstract}
Introduction. While there is relatively plenty of evidence of the positive impact of communication on the perceptions of organizational change, there is less evidence of how the perception of organizational change affects information sharing. This study investigates if a favourable perception of ongoing organizational changes has a positive impact on information sharing and whether trust mediates this relationship.
\end{abstract}

Method. A questionnaire $(N=317)$ was administered to the employees of a large Finnish multinational organization. Partial least square structural equation modelling (PLS-SEM) was used to test the hypotheses developed based on earlier research findings.

Results. The results show that a positive perception of recent organizational changes improves information sharing both directly and indirectly, mediated by trust. Consequently, when changes are perceived negatively, employees recoil from information sharing that, in turn, has been linked in earlier literature to different negative effects for organizations and their stakeholders.

Originality/value. This paper contributes to organizational information management research by elaborating on the relationship between small-scale organizational changes and interpersonal information sharing between employees. To our knowledge, this is the first quantitative study confirming the impact of perception of organizational changes on employee information-sharing behaviour.

\section{Introduction}

In the literature, there is broad consensus that information sharing is important for organizations. Based on a review of observed outcomes of information sharing versus information asymmetry, Tong and Crosno (2015) conclude that, in general, sharing leads to positive outcomes. The benefits are diverse, such as enhanced productivity, and creativity. In addition to positive organizational outcomes, individual-level knowledge sharing (in terms of attitudes and actualized behaviours) tends to have a positive impact on individual work performance (Henttonen et al., 2016). As information sharing plays an integral role in organizational success, the means to improve it has emerged as a focal area of investigation. Previous research has identified a number of factors - including organizational culture, diversity, personality, sense of coherence, and compensation - that influence information sharing between employees (Ahmad, 2017a; Shin, Ishman, and Sanders, 2007; Yang and Maxwell, 2011).

Recent technological developments, globalization, and rising competition have made organizations increasingly dynamic. Deployment of organizational change initiatives meant to reduce costs, develop competitive advantage, and adjust organizations to changing market conditions has become a truism (Cameron and Green, 2015; Worrall, Cooper and CampbellJamison, 2000). Previous studies show that persistent organizational changes not only affect work practices, but also induce variation in employees' attitudes, for example, in their organizational commitment, job satisfaction, and extra-role participation (Vakola, 2014; Worral, 2000). Although organizational changes are pervasive in today's organizations and they strongly influence employee behaviour, their implications for employees' informationsharing behaviour are largely unknown. Whereas there is relatively plenty of evidence of the 
positive impact of communication on the perceptions of organizational change, to the knowledge of the authors, there is less evidence of how the perception of organizational change affects information sharing. Hypothesizing that there is a similarly positive impact in the opposite direction, the aim of this study is to investigate if a favourable perception of ongoing organizational changes has a positive impact on information sharing.

This study makes a novel contribution to previous research by developing a better understanding of the relationship between information sharing and one of the most critical processes from the perspective of the long-term success of organizations, which is organizational change. Further, as there is plentiful of evidence that trust is a factor that relates both to information sharing and organizational change (e.g. Lines et al., 2005; Liu and Chetal, 2005; Ridings, Gefen, and Arinze, 2002; Wilson, 2010), we investigate its role in the equation. A better understanding of this relationship is not only useful for developing effective information management policies in organizations operating in highly dynamic industries, but it is also critical for the development and successful implementation of change initiatives.

\section{Literature review}

As Pilerot (2012) has shown, the term information sharing has been used to refer to a range of collaborative information giving and receiving activities with varying levels of specificity. Sometimes, information sharing is used to refer to the phenomena of giving and receiving (Savolainen, 2007), exchanging (e.g., Burnett, 2000; Hazel et al., 2010; Hersberger, 2003), reciprocal information sharing (Fulton, 2009; Huotari and Chatman, 2001), and collaborative information seeking (e.g., Hertzum, 2008). In a narrower sense, it can be seen as directive sharing (Talja, 2002) or, as sometimes found in the management literature, top-down dissemination (e.g., Brown and Cregan, 2008). Wittel (2011) proposed that changes in a technology environment could have a broader impact on sharing in general. Earlier, sharing was more markedly a question of exchange, but digital technologies have changed it to a hybrid of exchange and distribution (Wittel, 2011). Considering the specific activities described in different studies, the terms information sharing and knowledge sharing can be used interchangeably (Savolainen, 2017). Some researchers have been doing this for some time (e.g., Ahmad, 2017b; Widén-Wulff, 2007). In this study, we focus on information sharing at the interpersonal level, that is, exchange of work-related information between employees within an organization.

Earlier research has suggested that, in general, sharing leads to positive outcomes, whereas withholding and asymmetry of information tend to have negative outcomes (Tong and Crosno, 2015). Sharing is a prerequisite for becoming informed (e.g., Khoir et al., 2015), it plays a role in the emergence of social capital (Huvila et al., 2014), it is an integral aspect of information practices (Almehmadi et al., 2014; Du, 2014), and it is critical for successful work in many contexts (Choo et al., 2006). In teams, it contributes to team performance, cohesion, and knowledge integration (Mesmer-Magnus and DeChurch, 2009). Information sharing is also important for decision-making in groups (Mishra, 2014). Many of the same factors, most notably trust (Wilson, 2010), but also, for instance, social capital (Tötterman and Widén-Wulff, 2007) have been recognized also as antecedents to information sharing. The specific significance of trust has been explained by the critical importance of social integration in information sharing, in comparison to, for instance, technical infrastructures or external incentives (Hall and Widén-Wulff, 2008).

Positive outcomes have been observed to be related to sharing at both organizational and individual levels (Henttonen et al., 2016). On an organizational level, increased sharing has been suggested to lead to a positive organizational culture (Singh and Soltani, 2010) and changes in organizational culture have been suggested as a means to improve information 
sharing (Maras, 2017). In Pilerot's study, information sharing functioned as a "unifying force" directed towards establishing a discipline of design research (Pilerot, 2014) by forming a collective understanding of a common project (Pilerot and Limberg, 2011). Furthermore, social information processing theory suggests that employees' sense of organizational reality builds on how it is communicated with their closest colleagues (Salancik and Pfeffer, 1978), i.e. essentially, information sharing.

There are, however, opposite findings. Kembro and Näslund (2014) have reviewed empirical supply-chain management literature and failed to find hard evidence of the positive impact of information sharing in that specific context. Moreover, the review by Tong and Crosno (2015) shows that, in some cases, information sharing with external actors have led, for instance, to decreased performance and trust. A plausible explanation of these contradictory findings is that the benefits of information depend on context and situation. Richardson and Asthana (2005) note that the degree of information sharing can be placed on a continuum that ranges from overly open to too closed and chaotic, with an ideal level in the middle. Yang and Wu (2015) identified a number of criteria (categorized in four constructs: information quality, system quality, service quality, and public system service) according to which their participants from Taiwanese government agencies assessed the effectiveness of interorganizational information sharing.

Overall, information sharing and its antecedents and consequences have been investigated from different perspectives. As the reviewed literature shows, there is broad consensus that trust is both an outcome and an antecedent of information sharing. Nevertheless, what is important from the perspective of this study and its focus, in comparison to many other aspects, is that there is less evidence of how the perception of ongoing organizational changes influences information sharing between employees. Organizational changes are frequent and contribute to organizational dynamism through introducing variation in existing work practices and workplace conditions (Burke, 2017; Skogstad,et al., 2007). As information sharing practices are embedded in day-to-day work practices and routines (Forster, 2017; Widen \& Karim, 2018), any changes in organizational policies and environment could influence employee information sharing behaviour. Nevertheless, this relationship has not been explored before. This study tries to fill this research gap and explores the impact of organizational changes on information sharing in organizations.

\section{Hypotheses}

\section{Organizational changes and information sharing}

Organizational change refers to new ways of organizing and working (Brown and Cregan, 2008). Organizations continually re-evaluate their operational procedures and adjust them to changing market conditions. Radical organizational changes such as mergers and acquisitions, development of new ventures, and change of ownership occur less frequently (Holbeche, 2006). Conversely, small-scale changes such as adoption of new technologies, adjustment in the organizational structure, and introduction of new personnel policy and benefits are more frequent (Jones et al., 2008). Such changes are meant to enhance organizational performance through incremental improvements in the organization's internal work procedures and, in a general sense, in how things are done in practice. According to Ferwerda (2011), employees' positive perception of organizational changes influences their engagement in extra-role obligations such as information sharing. Moreover, changes also lead to a need for and an orientative seeking of new information (Byström, 1999). Ross (2004) described how the culture of sharing and openness changed due to the perceived and experienced change in New York's Silicon Alley when the Internet bubble burst at the turn of the millennium. Stenberg (2012) likewise noted that the resistance to ongoing change can impede information sharing. 
At a more general level, perceptions and attitudes towards change have been found to play a major role in the success of such change as well as in job attitudes, organizational commitment, and, for instance, occupational stress (Ferwerda, 2011; Vakola and Nikolaou, 2005). All these factors are commonly known as drivers of information sharing. Based on the previous discussion, we propose the following hypothesis.

H1: Positive perception of change enhances information sharing among employees.

\section{Trust as a mediator}

Trust refers to the confidence in the "other party's goodwill" and reflects the "faith in the integrity of the other party" (Piderit and Flowerday, 2014, p.81). Organizational changes can transform the existing social relationships and psychological work environment, thereby influencing trust among employees and in the management (Self and Schraeder, 2009). Trust is not a static cognitive condition (Schoorman, Mayer \& Davis 2007). In dynamic organizational environments, changing events lead to continuous assessment and readjustment of trust. Lines et al. (2005) show that when employees experience changes positively and find such changes to be aligned with their personal goals and interests, their trust on the management of the organization strengthens. In broader terms, a positive perception of change leads to that employees favour the change and accept the insightfulness of management as epitomized in new rules and regulations. At the extreme, every change is a demonstration of the competence and benevolence of the management that defines post change trust on management if the change is accepted or not (Knoll \& Gill, 2011; Line et al., 2005; Morgan \& Zeffane, 2003).

The uncertainty and dynamism of organizational changes also lead to a re-evaluation of trust relationships among employees. Individuals are more likely to trust others in a stable environment (Lines et al., 2005). Conversely, they become more suspicious in an uncertain milieu and try to assess how their peers support their position in newly defined environments. Particularly the employees with views not aligned with others', risk to lose trust on each other. Negative changes are known to create an environment of fear and insecurity, which, according to Kiefer (2005), leads to social withdrawal. Employees fear talking openly about their concerns (Ryan \& Oestreich, 1998) and hence, their circle of trust becomes smaller and smaller as the situation prolongs. Moreover, previous research shows that a positive perception of change enhance job satisfaction (Rafferty \& Griffin, 2006), job commitment (Fedor, Caldwell \& Herold, 2006) and employee wellbeing (Helliwell \& Huang, 2010). All these factors are also known as antecedents of trust in workplace (Kramer, 2006).

Similarly to the documented relation of organizational change and trust, previous research has indicated also a positive impact of trust on information sharing (Liu and Chetal, 2005; Ridings, Gefen, and Arinze, 2002; Wilson, 2010) and knowledge creation through information sharing. An individual's belief that the co-workers will not take advantage of the received information and will provide reliable information whenever needed is integral to the development of an information sharing culture in organizations (Gill and Thompson, 2017; Sankowska, 2013). Trust in management is equally important for information sharing because management decisions that protect employees' interests enhance employees' commitment and motivation to get involved in extra-role activities (Allen et al., 2007; Line et al., 2005).

According to Wilson's (1983) influential theory, people construct knowledge based on their first-hand experiences and by learning second-hand from people they trust. In sum, it has been suggested that social integration, trust, and information exchange are closely related to each other (Hall and Widén-Wulff, 2008). This means that trust, plausibly both horizontal among employees (Bowker and Villamizar, 2017) and vertical towards management (Allen and Wilson, 2003), plays an integral role in the change-information sharing relationship. 
Based on these earlier findings, we propose the following second hypothesis.

$\mathrm{H} 2$ : Trust mediates the relationship between perception of change and information sharing.

\section{Methods and materials}

\section{Data}

The sample of this study consisted of managerial- and operational-level employees working in a large Finnish multinational organization. The organization develops power solutions ranging from ship machinery to power plants for marine and energy markets. Data were collected in 2016 via an electronic questionnaire administered through the organization's internal online survey system. We received 400 responses, out of which 317 were useable and hence included in this study. Only employees who have experienced change in last 3 three years were included in this study. Around $65 \%$ of the respondents were male and $35 \%$ were female. Respondents worked in different areas including marketing, human resources, research and development, sales, communication, engineering, and strategy development.

Responses to the questionnaire were measured with a 7-point Likert scale. All variables were measured using scales based on previous studies. Perception of organizational changes was measured with formative indicators adapted from Jones et al. (2008) and Parent-Thirion et al. (2012). Perception was measured against four commonly occurring small-scale changes - new processes or technologies, new management procedures, new recruitments, new work time arrangements - as identified in Parent-Thirion et al. (2012). Employees were first asked whether they had experienced the particular form of change in the last 3 years or not. Only if they answered positively were they asked to rate their view on the respective change on a scale from 1 (very negative) to 7 (very positive).

Trust was measured using a two-item scale adopted from Ayoko and Pekerti (2008) that measures experienced trust towards colleagues and management. To be able to measure trust and change in a large heterogeneous context and also to be able to measure these constructs as systemic and generic phenomena (Huvila, 2017) rather than as traits related to specific individuals and authorities (e.g., Khvatova et al., 2016), the present study focused on experienced trust and change (i.e., essentially self-beliefs) rather than trust and change as specific actions (Dietz and Den Hartog, 2006; McEvily and Tortoriello, 2011).

Interpersonal information sharing includes both sending and receiving information. Davenport and Prusak (1998) established that information and knowledge sharing are twoway processes involving sending and receiving information. In order to measure information sharing, we adopted scale from Foss et al. (2009). We asked respondents about the extent to which they engage in sending and receiving information with their senior and junior colleagues. Variables used in this study along with the measurement items and sources are shown in the Table 1.

As shown in an earlier study, the size of personal information network defines the information sharing potential (Ahmad, 2017). Small interpersonal network represents a constrained information environment. Consequently, information network size may act as a suppressor in the proposed hypotheses. The influence of perception of change will not appear if information sharing is already constrained by small network connections. Therefore, we included information network size as a control variable in our model. We measured the size of personal information network using a Sociometric technique (Hlebec \& Kogovšek, 2013). Each respondent was asked to name the individuals who are important source of work related advice and professional information (Ibarra, 1992). From this information, we estimated their ego information network size. 
Table 1. Measurement model evaluation results

\begin{tabular}{|c|c|c|c|c|}
\hline Constructs & Loadings & $\mathrm{CR}$ & Alpha & AVE \\
\hline $\begin{array}{l}\text { Information sharing } \\
\text { - I share work related information with my colleagues in my } \\
\text { own } \\
\text { organization. }\end{array}$ & 0.74 & 0.88 & 0.80 & 0.55 \\
\hline $\begin{array}{l}\text { - I share work related information with my superiors. } \\
\text { - I share work related information with my junior colleagues in } \\
\text { my own organization. } \\
\text { - My colleagues in my own organization share a lot of work } \\
\text { related information with me. } \\
\text { - My junior colleagues in my own organization share a lot of } \\
\text { information with me. }\end{array}$ & $\begin{array}{l}0.62 \\
0.67 \\
0.68 \\
0.77\end{array}$ & & & \\
\hline - My superiors share a lot of work related information with me. & 0.74 & & & \\
\hline Trust & & 0.87 & 0.66 & 0.77 \\
\hline - I trust in management at my workplace. & 0.90 & & & \\
\hline - I trust my co-workers at my workplace. & 0.83 & & & \\
\hline $\begin{array}{l}\text { Perception of organizational changes - formative construct } \\
\text { - New processes or technologies were introduced in the } \\
\text { organization. } \\
\text { - New management procedures were introduced in the } \\
\text { organization. }\end{array}$ & $\begin{array}{l}- \\
-\end{array}$ & - & $\begin{array}{l}- \\
- \\
-\end{array}$ & $\begin{array}{l}- \\
-\end{array}$ \\
\hline - Recruitment of new employees was carried out. & - & - & - & - \\
\hline - Changes in working time arrangements were introduced. & - & - & - & - \\
\hline
\end{tabular}

\section{Data analysis}

Partial least square structural equation modelling (PLS-SEM) was used to analyse the data and to explore both direct and indirect effects of organizational changes on information sharing. PLS-SEM is a second-generation statistical technique that allows the measurement of reliability and validity of constructs and the estimation of the relationships between them simultaneously (Castro and Roldan, 2013). Moreover, this technique is useful for theoretical development and small sample sizes (Hair et al., 2017). We conducted the analysis with Smart PLS 3.0 (Ringle, Wende and Becker, 2015). The measurement model was evaluated before the structural model.

\section{Reliability and validity assessment}

In our model, we operationalized information sharing and trust as reflective constructs, and perception of organizational changes as a formative construct. In a reflective construct, measurement indicators are caused by the latent variable (Christophersen and Konradt, 2012). These indicators are interchangeable and have strong correlations, as they tend to measure the same thing. In a formative construct, the direction of the relationships between a latent variable and its indicators is opposite, which means that the construct's indicators are its defining characteristics (Jarvis et al., 2003). They do not act as manifestations and are not interchangeable like reflective indicators (Gable, 2009; Jarvis et al., 2003). We define the perception of organizational changes as a formative construct because employees may have different attitudes toward different organizational changes. An employee can perceive the introduction of a new management procedure as positive, but at the same time may have a negative attitude towards another change, for example, work time allocation. This means that indicators of perception of organizational changes are not interchangeable and are not necessarily correlated; hence, the construct should be treated as formative. In the following discussion, we will present the analysis of the quality of the reflective constructs followed by 
the formative construct.

The reflective constructs - information sharing and trust - were assessed for reliability (indicator reliability, internal consistency reliability) and validity (convergent and discriminant validity). Indicator reliability represents "variation in an item explained by the construct" and can be assessed with the loadings of indicators (Hair et al., 2013, p. 115). As shown in the Table 1, the loadings of measurement indicators of information sharing and trust are all above the threshold value of 0.60 (Chin, 1998; Henseler et al., 2009), which confirms indicator reliability. Internal consistency reliability, which refers to the "consistency of the results across measurement indicators," was assessed with Cronbach's alpha and composite reliability values (Hair et al., 2013, p. 116). All the indicators of information sharing and trust have composite reliability values above the recommended value of 0.70 (Hair et al., 2017; Henseler et al., 2009). Although trust has Cronbach alpha less than 0.70, it shows high composite reliability of 0.87 , which according to Hensler et al (2009) is more suitable for assessing reliability than Cronbach alpha in structural equation modeling. Overall, tests showed that the reflective measurement model has satisfactory reliability.

To assess convergent validity - the degree to which indicators of the same construct are correlated - average variance extracted (AVE) value of each construct was calculated. As shown in the Table 1, the AVE value of each construct is above the recommended threshold of 0.50, hence establishing convergent validity (Amaro and Duarte, 2015). Discriminant validity - the degree of distinctness between indicators of different constructs - was assessed using the Fornell and Larcker criterion - the AVE of each construct should be higher than its correlation with other constructs (Wong, 2013). Results are shown in the Table 2; boldfaced results are higher than all other values within rows and columns, which confirms discriminant validity of information sharing and trust.

Traditional reliability and validity analysis cannot be used to evaluate the quality of a formative construct (Gable, 2009), that is, perception of organizational changes. Nevertheless, Becker et al. (2013) outlined two methods to assess the quality of formative measurement scales. First, indicators' variance inflation factor (VIF) and tolerance values are computed to detect multicollinearity. Our analysis did not find any collinearity issues, as VIF values of the formative indicators of perception of organizational changes were lower than the recommend threshold of 4 , and tolerance of the indicators was higher than 0.50 . Second, outer weights of a formative construct's indicators should be significant, or their outer loadings should be above 0.50 . Three measurement indicators of perception of organizational changes had significant weights, whereas the fourth one was nonsignificant but had an outer loading higher than 0.50 . Therefore, we retained all the indicators.

Table 2. Discriminant validity assessment

\begin{tabular}{lrl} 
& 1 & 2 \\
\hline Information sharing & $\mathbf{0 . 7 4}$ & \\
Trust & 0.33 & $\mathbf{0 . 8 8}$ \\
\hline Bold numbers represent the square roots of the AVEs. &
\end{tabular}

The measurement model assessment shows that all reflective and formative constructs are reliable and valid; therefore, we proceed to test the model.

\section{Results}

Since the measurement model has provided the evidence of reliability and validity, standardized path coefficients and significance levels were examined for testing hypotheses. To test the direct and indirect effects, we followed the guidelines given by Hair et al. (2017) and Zhao et al., (2010), and evaluated the complete model at once. Figure 1 shows the path coefficients and significance levels. 


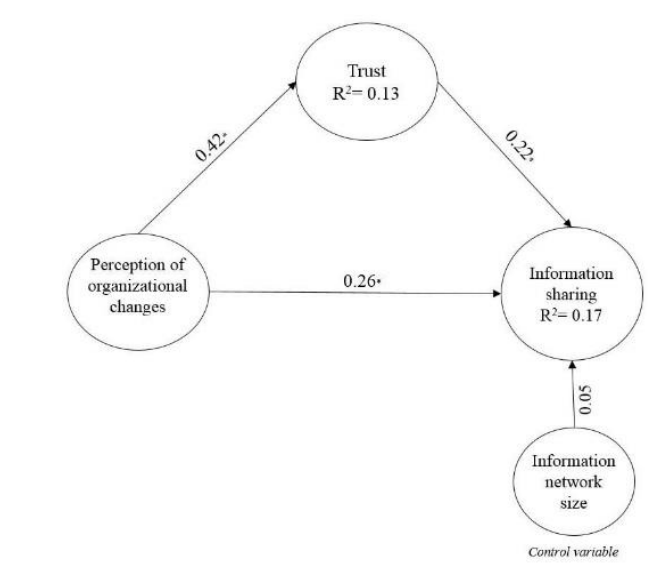

Fig. 1. Structural model with mediator Notes: $* \mathrm{p}<0.01$, (two-sided test)

As can be seen from the figure 1, employees' perception of organizational change has a positive relationship with information sharing $(\beta=0.30, p<0.01)$, which confirms hypothesis 1. Moreover, the perception of organizational changes positively influences trust $(\beta=0.52, p$ $<.01)$, which in turn, leads to information sharing $(\beta=0.20, p<.01)$. The indirect effect of perception of organizational changes $(0.10)$ on information sharing via the mediator construct, trust, was also significant $(p<.01)$. The results show that trust mediates the relationship between perception of organizational changes and information sharing. Consequently, hypothesis 2 is also supported. Nevertheless, it is a complementary and partial mediation, as direct and indirect effects are both significant and point to the same direction (Hair et al., 2017; Zhao et al., 2010). It also shows that in addition to trust, there may also be other mediator(s), which can further explain the relationship between perception of organizational change and information sharing.

Overall, we can say that if recent organizational changes are perceived positively, trust between employees and in management increases, which consequently enhances information sharing.

\section{Discussion}

This study contributes to a better understanding of organizational change and information sharing relationship. The results show that a positive perception of recent organizational changes improves information sharing both directly and indirectly, mediated by trust. There are, however, some limitations in the present findings. Data were collected in a single organization. The nature of the specific changes in the studied organization and its particularities had undoubtedly an effect on respondents' perceptions. Therefore, it will be important to confirm these findings with studies conducted in other settings likewise to consider the possible impact of additional variables, particularly control variables, in the model. There are also specific issues, including the impact of the number and type of changes and information sharing, that warrant further inquiry.

The validity of the findings is, however, supported given that they were in accordance with extant literature on trust, information sharing and organizational change, even though, to our knowledge, this specific relationship had not been investigated empirically before. There is previous evidence of the positive impact of trust on information sharing (Wilson, 2010). Furthermore, since trust, positive perception of the organization, and information sharing have all been identified as both outcomes and antecedents of social capital (e.g., Vos and Schoemaker, 2006), it was plausible to expect that these constructs would be linked. In this sense, the present findings support earlier empirical and theoretical research that underline the 
bidirectional influence of the factors affecting information sharing; for instance, in the notion of social capital. In comparison to earlier findings on the impact of organizational culture on information sharing (Maras, 2017), the present results demonstrate that also positively perceived change in the organization itself (not only in its current culture) can improve information sharing. Moreover, even if our findings show that trust plays a role in the equation, a notable contribution of this study is that the direct link between perception of change and information sharing is still significant when trust is added to the equation. This means that even if trust mediates the relation, the perception of change is directly linked to information sharing. Although the perception of change and organizational culture have a mutually reinforcing relationship (Austin and Ciaassen, 2008), the impact of organizational changes on information sharing is more evident due to their concrete implications for work practices. It is also plausible that perception of change acts as a boundary condition for the organizational culture-information sharing relationship.

An aspect that makes our findings especially significant is that can shed light to the dynamics of organizational change and its impact on employees' opportunities to receive information. Because change can lead to a need of orientative seeking of new information and actual seeking (Byström, 1999), change is less likely to yield positive outcomes for the organization if this seeking is hampered by a decline in how colleagues share information. This can be a result of, for instance, negative perceptions or, as Sonnenwald (2006) has shown, of high stress, and that situations are perceived as extraordinary and complex. The present findings suggest, however, that a favourable perception of a problematic change can reduce its negative impact by leading to an increased trust and sharing of information.

The findings of this study nuance also the earlier observations that environmental stability plays an important role in defining information sharing practices among employees (Ahmad and Widen, 2015; Yang and Maxwell, 2011). Previous research has shown that environmental uncertainty not only influences the flow and direction of information sharing, but also the type of information being shared (Wang, Huang, and Yang, 2012). Allen et al. (2007) showed that employees become extremely cautious about information sharing, paying special attention to the credibility and source of the information, while operating in uncertain environments. Since organizational changes reflect dynamism in an environment (Allen et al., 2007), they constitute a par excellence condition that risk to increase the uncertainty of work - which would according to the earlier findings reduce information sharing. The present findings suggest, however, that if changes are perceived in positive light, employees' trust is not necessarily depleted and information sharing does not decline.

In earlier studies, there are also indications that changing work practices and policies signal change in the status quo, which can trigger unorthodox (Huvila, 2013), protective, and selfinterest driven behaviour among employees. Furthermore, as noted in many previous studies, employees resort to egoistic information-related behaviours such as information hoarding when they try to protect their position and authority in the workplace (Ahmad and Widen, 2015; Constant, Kiesler, and Sproull, 1994; Yang and Maxwell, 2011). Such behaviours are particularly pertinent during changes such as staff modifications (hiring, firing, or transferring employees), with concrete implications for work duties. There is, however, also opposite evidence suggesting that employees might also engage in constructive and positive novel information sharing behaviours (e.g. as in Huvila, 2013) when work practices and policies change. Current findings of the positive impact of favourable perception of change to trust and information sharing could be one explanation why this happens. If a change is perceived in favourable terms, instead of behaving egoistically when they lose trust in their employer and colleagues, people maintain their trust and engage in information sharing, which benefits the whole workplace.

The present findings have also practical implications. Similarly to how earlier literature has 
stressed the critical importance of information sharing for changing and forming organizational culture (Singh and Soltani, 2010), cohesion (Pilerot, 2014) and "common projects" (Pilerot and Limberg, 2011), our results underscore the formative importance of perceptions of organizational change for information sharing. In practice, the nature of information sharing, both as an outcome and an instrument, underlines the importance of keeping information and perceptions of changing organizational reality aligned. Through their impact on information sharing, organizational changes that are perceived positively can be expected to result in the success of such changes and in the capacity of organizations to evolve and innovate.

In practical terms, these results suggest the importance of implementing measures for addressing perceptions of change in addition to managing change itself. This can be especially important because the negative changes do not necessarily have a direct impact on work performance (e.g. Brown and Cregan, 2008; Johnson and O'Leary-Kelly, 2003). At the same time, however, the detrimental effect of negative perceptions of change through their impact on information sharing has potentially more serious long-term consequences for an organization (e.g. Ross, 2004) than the possible failure of a specific change or realization of its expected benefits. The importance of an effective communication of changes and their individual and organizational benefits goes beyond its direct impact on change implementation (e.g., Russ, 2008). Therefore, organizations need to focus on communicating changes not only to make them happen, but also to ensure that employees value them positively. By influencing how change is perceived, a successful communication of its benefits, rationale, and practicalities will have a direct impact not only on what is known about it, but also on how employees will proactively share the related necessary information in the future. Combined with earlier insights from change management literature, these findings can be interpreted to suggest that the communication of change to improve its perception could be further complemented by focusing on the development of effective feedback mechanisms. Change management research has shown that employees' negative attitudes and behavioural responses can be reduced by allowing them to voice their concerns and making them feel heard (Piderit, 2000). Therefore, organizations should try to establish a mechanism for employees to provide feedback and express their concerns during the implementation of important changes to curtail the negative implications of change for information sharing.

\section{Conclusions}

The main contribution of this study is that it increases our understanding of the links between organizational change and information sharing by showing that if organizational changes are perceived positively, trust between employees and in management will increase, which consequently will enhance information sharing. In addition, this analysis shows that the perception of change is linked to information sharing even when the mediating effect of trust is taken into account. This underlines the importance of ensuring not only the practical success of organizational changes, but also their esteem among employees. If it is not successful, there is a risk that negative perceptions will lead to decreased information sharing, which has been linked in earlier literature to different negative effects for organizations and their stakeholders.

Future research should investigate the relationship between organizational change and information sharing more comprehensively. An important aspect of this relationship to explore in the future would be whether extent of experienced changes matter for employee information-sharing behaviour. Extensive or continuous organizational changes, even when perceived positively, can create a volatile trust environment, where employees may become static and recoil from sharing information. In addition, it would be interesting to measure 
possible differences between experiences and beliefs, and actions i.e. how actual instances of information sharing are influenced by change and trust.

The time aspect, which was not considered in this study, will be important for thoroughly deciphering the dynamics of the relationship between organizational change and information sharing. As the change process proceeds, employees' perception of it may change- their initial positive perception may turn into a negative one and vice versa. What consequences this would have for employees' information sharing needs further investigation. Future research should explore this relationship longitudinally.

\section{References}

Ahmad, F. (2017a), "Knowledge-sharing networks: Language diversity, its causes, and consequences". Knowledge and Process Management, Vol.24 No.2, pp.139-151.

Ahmad, F. (2017b), "Knowledge sharing in a non-native language context: Challenges and strategies". Journal of Information Science, Vol.44 No.2, pp.248-264.

Ahmad, F., and Widén, G. (2015), "Language clustering and knowledge sharing in multilingual organizations: A social perspective on language". Journal of Information Science, Vol.41 No.4, pp.430-443.

Allen, D., and Wilson, T. (2003), "Vertical trust/mistrust during information strategy formation". International Journal of Information Management, Vo.23 No.3, pp.223-237.

Allen, J., Jimmieson, N. L., Bordia, P., and Irmer, B. E. (2007), "Uncertainty during organizational change: Managing perceptions through communication”. Journal of Change Management, Vol.7 No.2, pp.187-210.

Almehmadi, F., Hepworth, M. and Maynard, S. (2014), “A framework for understanding information sharing: an exploration of the information sharing experiences of female academics in Saudi Arabia", Information Research, Vol.19 No.4.

Amaro, S. and Duarte, P. (2015), "An integrative model of consumers' intentions to purchase travel online", Tourism management, Vol.46, pp. 64-79.

Austin, M. J. and Ciaassen, J. (2008), "Impact of organizational change on organizational culture: Implications for introducing evidence-based practice", Journal of EvidenceBased Social Work, Vol.5 No.1-2, pp. 321-359.

Bowker, L., and Villamizar, C. (2017). "Embedding a records manager as a strategy for helping to positively influence an organization's records management culture". Records Management Journal, Vol.27 No.1, pp.57-68.

Brown, M. and Cregan, C. (2008), "Organizational change cynicism: The role of employee involvement", Humane Resource Management. Vol.47 No.4, pp. 667-686.

Burke, W. W. (2017), Organization change: Theory and practice. Sage Publications.

Skogstad, A., Matthiesen, S. B., and Einarsen, S. (2007), "Organizational changes: a precursor of bullying at work?", International Journal of Organization Theory \& Behavior, Vol. 10 No.1, pp. 58-94.

Burnett, G. (2000), "Information exchange in virtual communities: a typology", Information Research, Vol.5 No.4.

Byström, K. (1999), “Task Complexity, Information Types and Information Sources”, University of Tampere, Tampere.

Cameron, E., and Green, M. (2015). Making sense of change management: A complete guide to the models, tools and techniques of organizational change. Kogan Page Publishers.

Castro, I., and Roldán, J. L. (2013), "A mediation model between dimensions of social capital”, International Business Review, Vol.22 No.6, pp. 1034-1050.

Chin, W. W. (1998), "Commentary: issues and opinion on structural equation modeling”, MIS Quarterly, Vol.22 No.1, pp. 7-16. 
Choo, C.W., Furness, C., Paquette, S., van den Berg, H, Detlor, B., Bergeron, P. and Heaton, L. (2006), "Working with information: information management and culture in a professional services organization". Journal of Information Science, Vol. 32 No. 6, pp. 491- 510.

Christophersen, T. and Konradt, U. (2012). "Development and validation of a formative and a reflective measure for the assessment of online store usability". Behaviour \& Information Technology, Vol.31 No. 9, pp. 839-857.

$\mathrm{Du}, \mathrm{J}$. T. (2014), “The information journey of marketing professionals: Incorporating work task-driven information seeking, information judgments, information use, and information sharing", JASIST, Vol.65 No.9, pp. 1850-1869.

Fedor, D. B., Caldwell, S., and Herold, D. M. (2006), "The effects of organizational changes on employee commitment: A multilevel investigation”. Personnel Psychology, Vol.59 No.1, pp.1-29.

Ferwerda, J. (2011), "Perceptions of organizational change and the psychological contract", University of Tilburg.

Fornell, C. and Larcker, D. F. (1981), "Evaluating structural equation models with unobservable variables and measurement error", Journal of marketing research, Vol.28 No.1, pp. 39-50.

Forster, M. (2017), Information literacy in the workplace. Facet Publishing.

Foss, N. J., Minbaeva, D. B., Pedersen, T. and Reinholt, M. (2009), "Encouraging knowledge sharing among employees: How job design matters", Human resource management, Vol.48 No.6, pp. 871-893.

Fulton, C. (2009), "Quid Pro Quo: Information Sharing in Leisure Activities", Library Trends, Vol.57 No.4, pp. 753-768.

Gal, U., Lyytinen, K. and Yoo, Y. (2008), "The dynamics of it boundary objects, information infrastructures, and organisational identities: the introduction of $3 \mathrm{~d}$ modelling technologies into the architecture, engineering, and construction industry", European Journal of Information Systems, Vol.17 No.3, pp. 290-304.

Gill R. and Thompson M.M. (2017), "Trust and Information Sharing in MultinationalMultiagency Teams". In: Goldenberg I., Soeters J. and Dean W. (eds) Information Sharing in Military Operations. Advanced Sciences and Technologies for Security Applications. Springer, Cham

Hair Jr, J. F., Hult, G. T. M., Ringle, C. and Sarstedt, M. (2013), “A primer on partial least squares structural equation modeling (PLS-SEM)", Sage Publications.

Hair Jr, J. F., Hult, G. T. M., Ringle, C., and Sarstedt, M. (2017), A primer on partial least squares structural equation modeling (PLS-SEM). Sage Publications.

Hall, H., and Widen G., (2008), "Social exchange, social capital and information sharing in online environments: lessons from three case studies". In M.-L. Huotari and E.

Davenport, M.-L. Huotari and E. Davenport (Eds.), From information provision to knowledge production. Proceedings of the international conference for the celebration of the $20^{\text {th }}$ anniversary of Information Studies, Faculty of Humanities, University of Oulu, Finland, June 23-25, Vol. 8, pp. 73-86. Oulu: Oulu University Press.

Hall, H., Widén, G. and Paterson, L. (2010), "Not what you know, nor who you know, but who you know already: Examining online information sharing behaviours in a blogging environment through the lens of social exchange theory", Libri, Vol.60 No.2, pp. 117128.

Helliwell, J. F., and Huang, H. (2010), "How's the job? Well-being and social capital in the workplace", ILR Review, Vol.63 No.2, pp. 205-227.

Henseler, J., Ringle, C. M., and Sinkovics, R. R. (2009), "The use of partial least squares path modeling in international marketing", Advances in International Marketing, Vol.20, 
pp.277-319.

Henttonen, K., Kianto, A. and Ritala, P. (2016), "Knowledge sharing and individual work performance: an empirical study of a public sector organisation", Journal of Knowledge Management, Vol.20 No.4, pp. 749-768.

Hersberger, J. (2003), “A qualitative approach to examining information transfer via social networks among homeless populations", The New Review of Information Behaviour Research, Vol.4 No.1, pp. 95-108.

Hertzum, M. (2008), "Collaborative information seeking: The combined activity of information seeking and collaborative grounding", Information Processing \& Management, Vol.44 No.2, pp. 957-962.

Henseler, J., Ringle, C. M., and Sinkovics, R. R. (2009), "The use of partial least squares path modeling in international marketing". Advances in International Marketing, Vol.20 No.1, pp. 277-319.

Holbeche, L. (2006), Understanding change: Theory, implementation and success", Butterworth-Heinemann.

Huotari, M. and Chatman, E. (2001), "Using everyday life information seeking to explain organizational behavior", Library \& Information Science Research, Vol.23 No.4, pp. $351-366$.

Huvila, I. (2014), “Towards information leadership". Aslib Journal of Information Management, Vol.66 No.6, pp.663-677.

Huvila, I. (2017), "Distrust, mistrust, untrust and information practices", Information Research, Vol.22 No.1.

Huvila, I., Ek, S. and Widén, G. (2014), "Information sharing and the dimensions of social capital in Second Life", Journal of Information Science, Vol.40 No.2, pp. 237-248.

Jarvis, C. B., MacKenzie, S. B., and Podsakoff, P. M. (2003), “A critical review of construct indicators and measurement model misspecification in marketing and consumer research", Journal of consumer research, Vol.30 No.2, pp. 199-218.

Johnson, J. L. and O'Leary-Kelly, A. M. (2003), "The effects of psychological contract breach and organizational cynicism: not all social exchange violations are created equal", Journal of Organization Behaviour, Vol.24 No.5, pp. 627-647.

Jones, L., Watson, B., Hobman, E., Bordia, P., Gallois, C., and Callan, V. J. (2008), "Employee perceptions of organizational change: impact of hierarchical level", Leadership \& Organization Development Journal, Vol.29 No.4, pp. 294-316.

Kembro, J. and Näslund, D. (2014), "Information sharing in supply chains, myth or reality? a critical analysis of empirical literature", International Journal of Physical Distribution \& Logistics Management, Vol.44 No.3, pp. 179-200.

Khoir, S., Du, J. T. and Koronios, A. (2015), "Everyday information behaviour of Asian immigrants in South Australia: a mixed-methods exploration", Information Reseach, Vol.20 No.3.

Khvatova, T., Block, M., Zhukov, D., and Lesko, S. (2016), "How to measure trust: the percolation model applied to intra-organisational knowledge sharing networks". Journal of Knowledge Management, Vol.20 No.5, pp. 918-935.

Kiefer, T. (2005), "Feeling bad: Antecedents and consequences of negative emotions in ongoing change". The International Journal of Industrial, Occupational and Organizational Psychology and Behavior, Vol.26 No.8, pp.875-897.

Knoll, D. L., and Gill, H. (2011), "Antecedents of trust in supervisors, subordinates, and peers", Journal of Managerial Psychology, Vol.26 No.4, pp.313-330.

Kramer, R. M. (Ed.). (2006), Organizational trust: A reader. Oxford University Press on Demand.

Lines, R., Selart, M., Espedal, B. and Johansen, S. T. (2005), "The production of trust during 
organizational change", Journal of Change Management, Vol.5 No.2, pp. 221-245.

Liu, P., and Chetal, A. (2005), "Trust-based secure information sharing between federal government agencies", Journal of the Association for Information Science and Technology, Vol.56 No.3, pp. 283-298.

Maras, M.-H. (2017), "Overcoming the intelligence-sharing paradox: Improving information sharing through change in organizational culture", Comparative Strategy, Vol.36 No.3, pp. 187-197.

McEvily, B., and Tortoriello, M. (2011), "Measuring trust in organisational research: Review and recommendations". Journal of Trust Research, Vol. 1, No. 1, pp. 23-63.

Mesmer-Magnus, J. R. and DeChurch, L. A. (2009), "Information sharing and team performance: A meta-analysis", Journal of Applied Psychology, Vol.94 No.2, pp. 535546.

Mishra, J. L. (2014), "Factors affecting group decision making: An insight on information practices by investigating decision making process among tactical commanders", Information Research, Vol.19 No.4.

Morgan, D. and Zeffane, R. (2003), "Employee involvement, organizational change and trust in management", The International Journal of Human Resource Management, Vol.14 No.1, pp. 55-75.

Parent-Thirion, A., Vermeylen, G., van Houten, G., Lyly-Yrjänäinen, M., Biletta, I., and Cabrita, J. (2012), Fifth European Working Conditions Survey-Overview Report", Luxembourg: Publications Office of the European Union.

Peel, M. and Rowley, J. (2010), "Information sharing practice in multi-agency working". Aslib Proceedings, Vol. 62 No. 1, pp. 11-28.

Petter, S., Straub, D., and Rai, A. (2007), "Specifying formative constructs in information systems research", MIS quarterly, Vol.31 No.4, pp. 623-656.

Piderit, R., and Flowerday, S. (2014), "The risk relationship between trust and information sharing in automotive supply chains". In Internet Security (WorldCIS), 2014 World Congress, IEEE, pp. 80-85.

Piderit, S. K. (2000). "Rethinking resistance and recognizing ambivalence: A multidimensional view of attitudes toward an organizational change". Academy of Management Review, Vol. 25 No. 4, pp.783-794.

Pilerot, O. (2012), "LIS research on information sharing activities - people, places, or information", Journal of Documentation, Vol.68 No.4, pp. 559-581.

Pilerot, O. (2014), "Design researchers' information sharing: the enactment of a discipline", University of Borås, Borås.

Pilerot, O. and Limberg, L. (2011), "Information sharing as a means to reach collective understanding: A study of design scholars information practices", Journal of Documentation, Vol.67 No.2, pp. 312-333.

Rafferty, A. E., and Griffin, M. A. (2006), "Perceptions of organizational change: A stress and coping perspective". Journal of applied psychology, Vol.91 No.5, pp.1154 -1162.

Richardson, S. and Asthana, S. (2005), "Policy and Legal Influences on Inter-Organisational Information Sharing in Health and Social Care Services", Journal of Integrated Care, Vol.13 No.3, pp. 3-10.

Ridings, C. M., Gefen, D., and Arinze, B. (2002), "Some antecedents and effects of trust in virtual communities", The Journal of Strategic Information Systems, Vol.11 No.3-4, pp. 271-295.

Ringle, Christian M., Wende, Sven, \& Becker, Jan-Michael. (2015). SmartPLS 3. Bönningstedt: SmartPLS. Retrieved from http://www.smartpls.com.

Ross, A. (2004), "No-collar: The humane workplace and its hidden costs", Temple University Press. 
Ryan, K. D., and Oestreich, D. K. (1998), Driving fear out of the workplace: Creating the high-trust, high-performance organization. Jossey-Bass.

Salancik, G. R. and Pfeffer, J. (1978), "A social information processing approach to job attitudes and task design", Administrative Science Quarterly, Vol.23 No.2, pp. 224-253.

Sankowska, A. (2013), "Relationships between organizational trust, knowledge transfer, knowledge creation, and firm's innovativeness". The Learning Organization, Vol.20 No.1, pp.85-100.

Savolainen, R. (2007), "Motives for giving information in non-work contexts and the expectations of reciprocity. The case of environmental activists", Proceedings of the Association for Information Science and Technology, Vol.44 No.1, pp. 1-13.

Savolainen, R. (2017), "Information sharing and knowledge sharing as communicative activities. Information Research, Vol.22 No.3.

Schoorman, F. D., Mayer, R. C., and Davis, J. H. (2007), “An integrative model of organizational trust: Past, present, and future", Academy of Management Review, Vol.32 No.2, pp.344-354.

Self, D. R. and Schraeder, M. (2009). "Enhancing the success of organizational change: Matching readiness strategies with sources of resistance". Leadership \& Organization Development Journal, Vol.30 No. 2, pp.167-182.

Shin, S. K., Ishman, M., and Sanders, G. L. (2007). "An empirical investigation of sociocultural factors of information sharing in China". Information \& Management, Vol. 44 No. 2, pp.165-174.

Singh, A. and Soltani, E. (2010), "Knowledge management practices in indian information technology companies", Total Quality Management \& Business Excellence, Vol.21 No.2, pp. $145-157$.

Sonnenwald, D. H. (2006), "Challenges in sharing information effectively: examples from command and control", Information Research, Vol.11 No.4.

Stenberg, M. (2012), "Tiedon jakaminen organisaatiossa: Kuinka aineetonta pääomaa kasvatetaan", University of Tampere, Tampere.

Talja, S. (2002), "Information sharing in academic communities: Types and levels of collaboration in information seeking and use", New Review of Information Behaviour, Vol.3 No.1, pp.143-159.

Tong, P. Y. and Crosno, J. L. (2015), "Are information asymmetry and sharing good, bad, or context dependent? A meta-analytic review", Industrial Marketing Management, Vol.56, pp.167-180.

Tötterman, A.K. and Widén-Wulff, G. (2007), "What a social capital perspective can bring to the understanding of information sharing in a university context", Information Research, Vol.12 No.4.

Vakola, M. (2014). "What's in there for me? Individual readiness to change and the perceived impact of organizational change". Leadership \& Organization Development Journal, Vol. 35 No.3, pp.195-209.

Vakola, M. and Nikolaou, I. (2005), "Attitudes towards organizational change: What is the role of employees' stress and commitment?”, Employee Relations, Vol.27 No.2, pp. 160174.

Vos, M. and Schoemaker, H. (2006), “Monitoring public perception of organisations”, Boom onderwijs, Amsterdam.

Widen G., Karim M. (2018) Role of Information Culture in Workplace Information Literacy: A Literature Review. In: Kurbanoğlu S., Boustany J., Špiranec S., Grassian E., Mizrachi D., Roy L. (eds) Information Literacy in the Workplace. ECIL 2017. Communications in Computer and Information Science, vol 810. Springer, Cham

Widén-Wulff, G. (2007), "Challenges of Knowledge Sharing in Practise: A Social 
Approach", Oxford: Chandos.

Wilson, P. (1983). Second-Hand Knowledge: An Inquiry into Cognitive Authority. Westport, CN: Greenwood Press.

Wilson, T. (2010), "Information sharing: an exploration of the literature and some propositions", Information Research, Vol.15 No.4.

Wittel, A. (2011), "Qualities of Sharing and their Transformations in the Digital Age", International Review of Information Ethics, Vol.15 No.9, pp.3-8.

Wong, K. K. K. (2013), "Partial least squares structural equation modeling (PLS-SEM) techniques using SmartPLS”, Marketing Bulletin, Vol.24 No.1, pp. 1-32.

Worrall, L., Cooper, C. L. and Campbell-Jamison, F. (2000). "The impact of organizational change on the work experiences and perceptions of public sector managers". Personnel Review, Vol. 29 No5, pp. 613-636.

Yang, T. M., and Maxwell, T. A. (2011). "Information-sharing in public organizations: A literature review of interpersonal, intra-organizational and inter-organizational success factors". Government Information Quarterly, Vo.28 No. 2, pp.164-175.

Yang, T.-M., and Wu, Y.-J. (2015), "Exploring the effectiveness of cross-boundary information sharing in the public sector: the perspective of government agencies", Information Research, Vol.20 No.3.

Zhao, X., Lynch, J.G., and Chen, Q., (2010), "Reconsidering Baron and Kenny: myths and truths about mediation analysis", Journal of Consumer Research Vol.37 No.3, pp.197206. 